\title{
Anti Tumoral Properties of Punica Granatum (Pomegranate) Peel Extract on Different Human Cancer Cells
}

\author{
Sina Modaeinama ${ }^{1}$, Mozhgan Abasi ${ }^{2}$, Mehran Mesgari Abbasi ${ }^{3,4}$, Rana Jahanban- \\ Esfahlan $^{2,4 *}$
}

\begin{abstract}
Background: Medicinal plants, especially examples rich in polyphenolic compounds, have been suggested to be chemopreventive on account of antioxidative properties. Punica granatum (PG) (pomegranate) is a well known fruit in this context, but its cytotoxicity in cancer cells has not been extensively studied. Here, we investigated the antiproliferative properties of a peel extract of PG from Iran in different human cancer cells. Materials and Methods: A methanolic extract of pomegranate peel (PPE) was prepared. Total phenolic content(TPC) and total flavonoid conetnt (TFC) were determined by colorimetric assays. Antioxidant activity was determined by DPPH radical scavenging activity. The cytotoxicity of different doses of PPE $(0,5,20,100,250,500,1000 \mu \mathrm{g} / \mathrm{ml})$ was evaluated by MTT assays with A549 (lung non small cell cancer), MCF-7 (breast adenocarcinoma), SKOV3 (ovarian cancer), and PC-3 (prostate adenocarcinoma) cells. Results: Significant $(\mathbf{P}<0.01)$ or very significant $(\mathbf{P}<\mathbf{0 . 0 0 0 1})$ differences were observed in comparison with negative controls at all tested doses $(5-1000 \mathrm{\mu g} / \mathrm{ml})$. In all studied cancer cells, PPE reduced the cell viability to values below $40 \%$, even at the lowest doses. In all cases, IC50 was determined at doses below $5 \mu \mathrm{g} / \mathrm{ml}$. In this regard, MCF-7 breast adenocarcinoma cells were the most responsive cells to antiprolifreative effects of PPE with a maximum mean growth inhibition of $81.0 \%$ vs. 69.4\%, 79.3\% and 77.5\% in SKOV3, PC-3 and A549 cells, respectively. Conclusions: Low doses of PPE exert potent anti-proliferative effects in different human cancer cells and it seems that MCF-7 breast adenocarcinoma cells are the most cells and SKOV3 ovarian cancer cells the least responsive in this regard. However, the mechanisms of action need to be addressed.
\end{abstract}

Keywords: Pomegranate peel extract (PPE) - A549 - SKOV3 - MCF-7 - PC-3 - anti-tumoral effects

Asian Pac J Cancer Prev, 16 (14), 5697-5701

\section{Introduction}

Because treatment options for advanced metastasized cancers stays insufficient, developing efficient methods to Figureht cancer has become a central aim to decrease cancer burden (Abbasi et al., 2014a). One such strategy is through chemoprevention, if possible by the use of nontoxic natural products. In this respect, Pomegranate, used for centuries in folk medicine is now being acknowledged as a potential chemopreventive and anticancer agent (Jahanban-Esfahlan et al., 2010; Valiyari et al., 2013; Abbasi et al., 2014b).

Punica granatum L. var. spinosa is known as apple punice from Punicaceae family generally common in the latitudes of $475 \mathrm{~m}$ above sea level in the north of Iran. Punica Granatum has been used widely in traditional medicine for treatment of diarrhea, dysentery, acidosis, helminthiasis, hemorrhage and respiratory disorders. The tree/fruit consist of several components as: seed, juice, peel, leaf, flower, bark, and roots, each of which exerts intriguing pharmacologic activity (Lansky and Newman, 2007).

The pomegranate fruits are rich in polyphenolic compounds including punicalagin isomers, ellagic acid derivatives and anthocyanins (delphinidin, cyanidin and pelargonidin 3-glucosides and 3,5-diglucosides) (Elango et al., 2011). Pomegranate is made of a rich variety of flavonoids, which contain approximately $0.2 \%$ to $1.0 \%$ of the fruit. About $30 \%$ of all anthocyanidins found in pomegranate are restricted within the peel. Poly phenolic compounds, as well as flavonoids and tannins are abundant in the peels of wild-crafted compared to cultivated fruits (Singh et al., 2002). Various fractions have been extracted from the pomegranate peel and seeds using ethyl acetate, methanol and water. It is shown that extraction with methanol give a higher yield with greater antioxidant activity. The peel exhibited higher activity as compared to seeds, ascribed to its phenolic composition (Syed et al., 2007).

Punica Granatum (PG) has been demonstrated to

${ }^{1}$ Department of Pharmacology and Toxicology, Faculty of Veterinary Medicine, Urmia University, Urmia, ${ }^{2}$ Department of Medical Biotechnology, Faculty of Advanced Medical Sciences, ${ }^{3}$ Student Research Committee, ${ }^{4}$ Drug Applied Research Center, Tabriz University of Medical Sciences, Tabriz, Iran *For correspondence: jahanbanr@tbzmed.ac.ir 


\section{Sina Modaeinama et al}

possess antitumor effects on various types of cancer cells and these flavonoid rich pomegranate phenolic fractions are responsible for anticancer activity. Despite the high concentration of anthocyanidins in the peel, the literature available regarding anticancer potential of pomegranate is focused mainly on the fruit juice or seed and very little data is available on peel of pomegranate (Elango et al., 2011). Iranian variety of pomegranate is having dark red peel which is the indicative of the presence of excess anthocyanins and other polyphenolic compounds. Hence in the present study, we have chosen the peel of Persian Pomegranate to investigate its anticarcinogenic activity in human A549 lung non small cell carcinoma, PC-3 human prostate cancer cells, SKOV3 Ovarian cancer cells and MCF-7 breast adenocarcinoma cancer cells through MTT assay.

\section{Materials and Methods}

\section{Preparation of extracts}

Pomegranate fruits were collected from Mazandaran province, Iran in 2014. The peel parts were separated, dried and grounded into fine powder using a blender. Extractions were performed in a Soxhlet apparatus with methanol. The extract were concentrated by rotary evaporator and then dried in very low pressure. The dried extracts were stored at $-20^{\circ} \mathrm{C}$. A stock of $10 \mathrm{mg}$ of extract were prepared in $1 \mathrm{~mL}$ dimethyl sulfoxide (DMSO) was filtered using $0.22 \mathrm{~mm}$ syringe filter. The percentage of DMSO in the experiment was kept below 0.5 ).

\section{Determination of Total phenolic content (TPC)}

Total phenolic content was determined with FolinCiocalteu Reagent (FCR) according to the a described method (Singleton and Rossi, 1965) with some modifications. Briefly, $0.5 \mathrm{ml}$ of each phenolic extract was mixed with $2 \mathrm{ml}$ of $7.5 \%$ sodium carbonate, and then the mixture was allowed to stand at room temperature for $2 \mathrm{~min}$. After addition of $2.5 \mathrm{ml}$ ten-fold Folin-Ciocalteu reagent, the mixture was incubated in the dark room for $30 \mathrm{~min}$. The absorbance was measured at $720 \mathrm{~nm}$ by using a spectrophotometer.The results were expressed as equivalent $\mathrm{mg}$ of Gallic acid per $100 \mathrm{~g}$ of fresh mass (mg
GAE/100 g FM). A standard curve for Gallic acid was plotted under the same conditions as the studied samples. All determinations were performed in triplicates.

\section{Determination of Total flavonoid content (TFC)}

Total flavonoid content of the extracts were assayed by the colorimetric method described by other authors (Zhishen et al., 1999; Jahanban-Esfahlan et al., 2012), with minor modifications. CME $(250 \mu \mathrm{l})$ was mixed with 1.25 $\mathrm{ml}$ of distilled water and $75 \mu \mathrm{l}$ of a $5 \% \mathrm{NaNO} 2$ solution. After five minutes, $150 \mu \mathrm{l}$ of a $10 \% \mathrm{AlCl} 3$. $\mathrm{H}_{2} \mathrm{O}$ solution, $500 \mu \mathrm{l}$ of $1 \mathrm{M} \mathrm{NaOH}$ and $275 \mu \mathrm{l}$ of distilled water were added to the mixture. The absorbance of the mixture was measured at $507 \mathrm{~nm}$. The results were expressed as equivalent $\mathrm{mg}$ of Qurcetin per $100 \mathrm{~g}$ of fresh mass (mg $\mathrm{Q} / 100 \mathrm{~g}$ FM) and compared with the Qurcetin standard curve, which was made under the same conditions. All determinations were performed in triplicates.

\section{DPPH free radical scavenging activity}

The DPPH radical scavenging activity was determined as described Brand-Williams et al. (1995) with some modifications. Various volumes of extracts (30, 50, 70 and $100 \mathrm{~mL}$ ) were added to $1 \mathrm{~mL}$ of 2, 2-diphenyl-1picrylhydrazyl (DPPH) solution $(0.1 \mathrm{mM}$ in methanol) and the reaction mixture shaken vigorously. After incubation at room temperature for $10 \mathrm{~min}$, the absorbance of this solution was determined at $517 \mathrm{~nm}$, by using a spectrophotometer. The antioxidant activity was expressed as $\mathrm{IC}_{50}$ values, which were calculated by non-linear regression with a one phase exponential association equation using GraphPad Prism version 6.0.

\section{Table 1. Growth Inhibition (72 h) Peel extract}

\begin{tabular}{lllll}
\hline $\begin{array}{l}\text { Doses } \\
(\mu \mathrm{g} / \mathrm{ml})\end{array}$ & SKOV3 & MCF-7 & PC-3 & A549 \\
\hline 1000 & $68.45 \pm 5.2$ & $81.3 \pm 7.2$ & $77.6 \pm 5.2$ & $79.62 \pm 7.1$ \\
500 & $63.87 \pm 3.0$ & $76.54 \pm 3.6$ & $84.0 \pm 3.0$ & $76.25 \pm 3.3$ \\
250 & $69.3 \pm 4.4$ & $82.0 \pm 2.4$ & $84.16 \pm 4.4$ & $80.0 \pm 4.9$ \\
100 & $78.2 \pm 6.1$ & $82.4 \pm 8.3$ & $78.5 \pm 6.1$ & $76.0 \pm 4.5$ \\
20 & $73.4 \pm 8.2$ & $80.25 \pm 5.4$ & $73.7 \pm 8.2$ & $76.4 \pm 6.7$ \\
5 & $63.41 \pm 7.1$ & $83.7 \pm 43$ & $77.87 \pm 7.1$ & $76.54 \pm 4.4$ \\
Mean \pm SEM & $69.43 \pm 4.5$ & $81.03 \pm 4.8$ & $79.3 \pm 7.7$ & $77.46 \pm 2.1$ \\
\hline
\end{tabular}
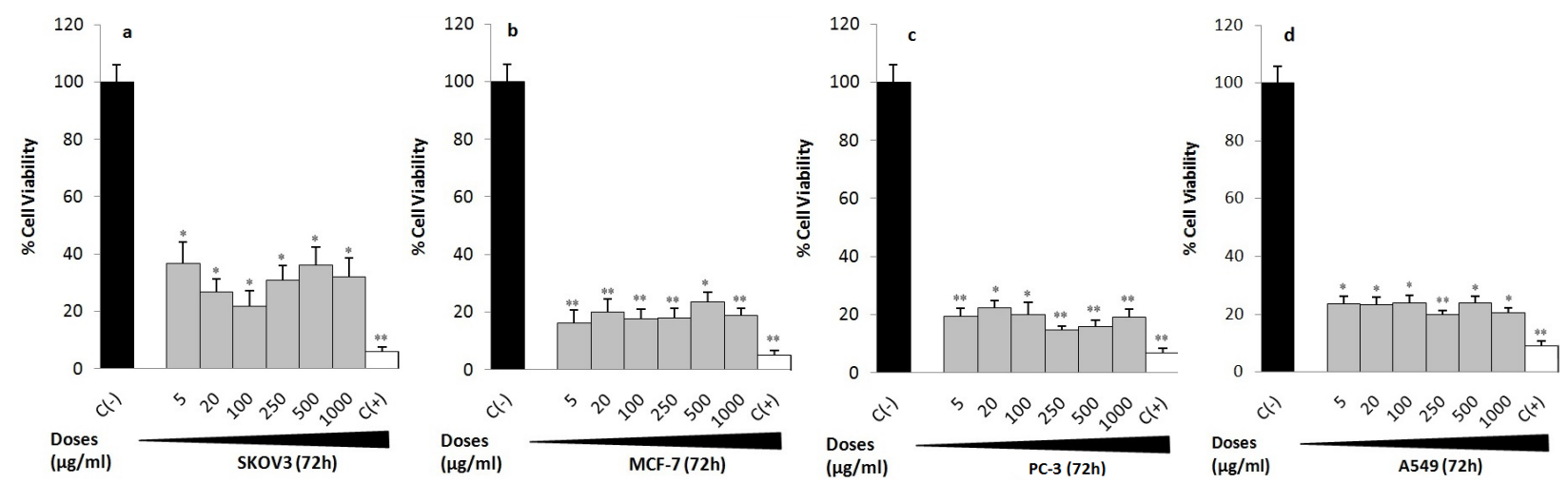

Negative control

$\square$ Extracts

Positive control

Figure 1. PPE Extract Inhibit Different Human Cancer Cell Proliferation. *p $<0.01 ; * * p<0.001$, Compared to the Negative Control 


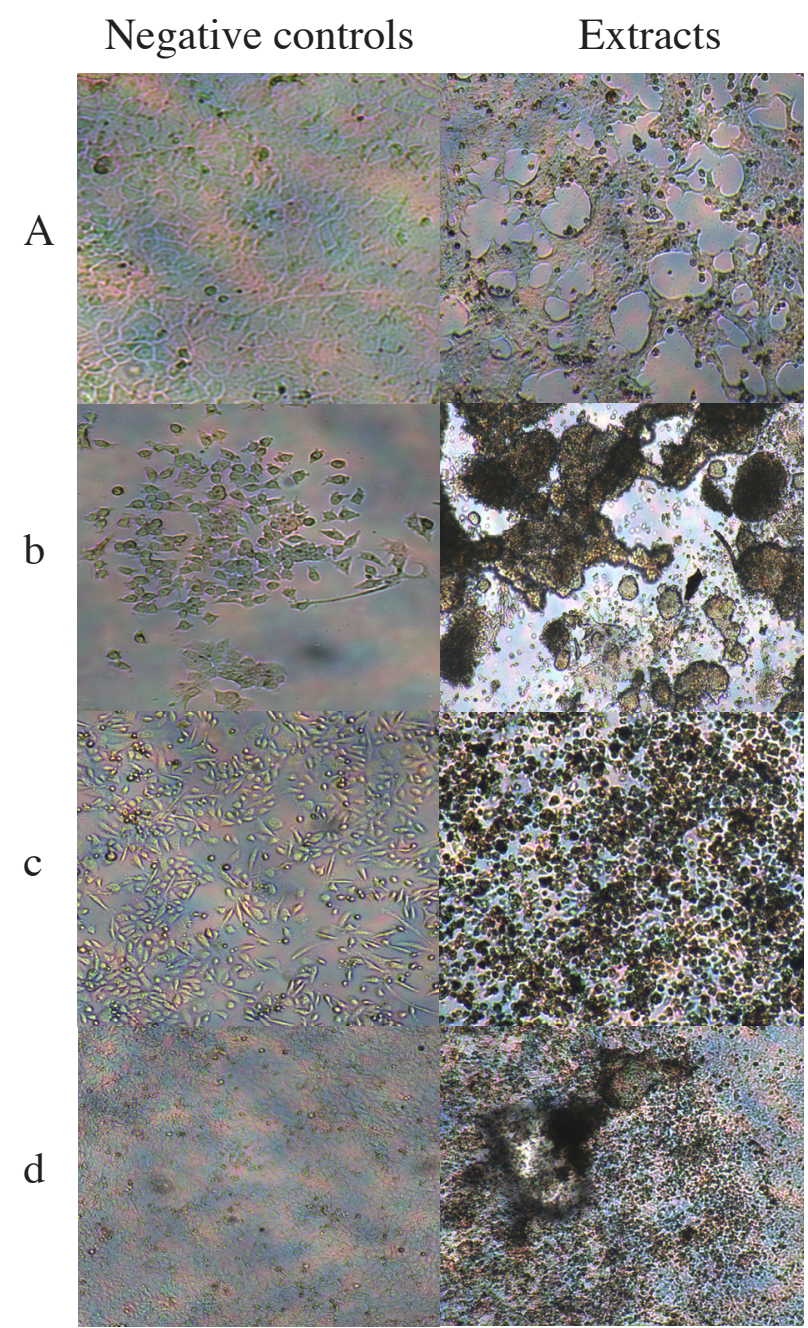

Figure 2. Cytotoxic Effect of PPE on Human SKOV3 (a), MCF-7 (b), PC-3(c) and A549 (d) Cell Lines after 72h Exposure

\section{Cell culture}

SKOV3 (human ovarian carcinoma), MCF-7(human breast adenocarcinoma), PC-3 (Human prostate adenocarcinima), A549 (lung non small cell cancer cells) were obtained from the Pasture Institute (Tehran- Iran). Cells were grown in RPMI 1640 supplemented with 10\% heat-inactivated fetal bovine serum (FBS), penicillin (10 $\mathrm{U} / \mathrm{ml})$, streptomycin $(10 \mu \mathrm{g} / \mathrm{ml})$ and $0.2 \mathrm{mM}$ sodium pyruvate. Cultures were incubated in the presence of 5\% $\mathrm{CO}_{2}$ at $37^{\circ} \mathrm{C}$ and $100 \%$ relative humidified atmosphere.

\section{MTT assay}

The cells were seeded in 96-well plates with a density of $1 \times 10^{4}$ cells $/$ well $/ 200 \mathrm{~mL}$ and incubated for $24 \mathrm{~h}$ at $37 \mathrm{C}$ and $5 \% \mathrm{CO}_{2}$. The cells were treated with different concentrations of solvent extracts $(5,20,100,250,500$, $1000 \mu \mathrm{g} / \mathrm{ml}$ ) and $0.2 \%$ (v/v) DMSO (Merck, Darmstadt, Germany) as a negative control. Paclitaxel (plant-derived chemotherapeutic anti-cancer drug from Taxus brevifolia) was used as a positive control. After $72 \mathrm{~h}$ treatment, 10 $\mathrm{mL}$ of MTT reagent was added to each well. The plates were incubated at $37^{\circ} \mathrm{C}$ and $5 \% \mathrm{CO}_{2}$ for $4 \mathrm{~h}$. Then, 100 $\mathrm{mL}$ of the solubilization solution was added to each well and followed by incubation overnight at $37^{\circ} \mathrm{C}$ to dissolve formazan crystals. Finally, absorbance was read using an ELISA plate reader at a wavelength of $570 \mathrm{~nm}$. The percentage of cytotoxicity and cell viability were calculated using following equation: \% Cytotoxicity=1(mean absorbance of treated cells/mean absorbance of negative control) and \% Viability $=100 \%$ Cytotoxicity.

\section{Statistical analysis}

All the data represented in this study are mean \pm SEM of three identical experiments made in three replicate. Statistical significance was determined by analysis of variance, followed by LSD test and $p$-value $\leq 0.01$ was considered significant. All analyses were conducted using the SPSS 16.

\section{Results and Discussion}

In the recent decades, although so much success accomplished in cancer treatment, however it still remains among the most common killers in the world (Jahanban Esfahlan et al., 2011). Universal cancer burden rises to 14.1 million new cases in 2012 and striking increase in breast cancers must be addressed. Furthermore, according to the 2014 cancer statistics in United Sates, Among men, cancers of the prostate, lung and bronchus, and colorectum will account for about $50 \%$ of all newly diagnosed cancers, as prostate cancer alone will account for $27 \%(233,000)$ of incident cases in men. At the other hand, cancers of breast, lung and bronchus, and colorectum, accounting for one-half of all cases in women. Breast cancer alone is expected to account for $29 \%(232,670)$ of all new cancers among women. Overall, cancers of the lung and bronchus, prostate, breast, and colorectum continue to be the most common causes of cancer death. These 4 cancers account for almost half of the total cancer deaths among men and women, with more than one-quarter of all cancer deaths due to lung cancer. An urgent need in cancer control today is to develop effective and affordable approaches to the early detection, diagnosis, and treatment of cancer(Abbasi et al., 2014c).

Among a plethora of treatment options, natural products especially those rich in antioxidant, always being regarded as a safe chemotherapeutic agents that effectively scavenge the hazardous free radicals and protect cells form their uncontrolled cell growth and so development of cancer (Abbasi et al., 2014c). Peel extract (PPE) native to Iran showed significant high amount of \% TFC (103.61 mg Q/100g FM) and \% TPC (1532.2 mg Q/100g FM). Moreover, DPPH IC $_{50}$ was determined $1.5 \mu \mathrm{g} / \mathrm{ml}$ for PPE which indicates to the high antioxidant activity of prepared extarct. The antioxidant capacity is described quantitatively by the concentration of antioxidant required to scavenge $50 \%$ of either $\mathrm{DPPH} \bullet$, which is referred as $\mathrm{IC}_{50}$.

Following, we investigated the selective cytotoxicity of PPE on a series of human cancers including ovarian cancer cells (SKOV3), breast adenocarcinoma cells (MCF-7), prostate adenocarcinoma cells (PC-3) and lung non small cancer cells (A549) by MTT assay. In the course of our interest on finding treatment option for aggressive tumors, we specially selected these cancer cells because each displays a high propensity for 
metastasis in vivo. It is shown that $\mathrm{MCF}-7$ cells form tumors when injected into athymic nude mice. These tumors are able to metastasize to lungs, liver and spleen. MCF-7 cells secrete into the culture media collagenases able to lyse types I and IV collagens (Shafie and Liotta, 1980). At the other hand, PC-3 cells have high metastatic potential to bone compared to other prostate cell lines such as DU145 cells which have a moderate metastatic potential and to LNCaP cells which have low metastatic potential (Sanchez-Sweatman et al., 1998). lung small cell adenocarcinoma is a rapid growth tumor with high propensity for invasion and metastasis. This cell line frequently use for induction of lung metastasis in mice (Shindo-Okada et al., 2002). Similar to MCF-7, SKOV3 cells are among the aggressive and the most coomon gynecologic cancer in women, however the unpredicted behavior of SKOV3 differ it from other ER+ cancer cells as well as MCF-7. Both MCF-7 and SKOV3 have the receptors for estrogen $(\mathrm{ER}+)$ and basically they should proliferate in response to estrogen ,however practically $\mathrm{ER}+\mathrm{SKOV} 3$ cells are irresponsive to both estrogen and its analogues and this feature makes it a good candidate for studding the mechanism by which ER+ cells become unresponsive to estrogen and anti-estrogen therapies. As some polyphenols can interfere with aromatase activity and so hinder synthesis of estrogen which acts as a main growth promoting factor on cancer cells, so we used both hormone responsive and irresponsive cells to discern the selective effects of high polyphenolic extract of PG fruit on these cells.

Our results indicated that in all doses, significant or very significant difference was observed between treated and untreated controls in a dose independent manner (Figure 1,2). In all cell lines, $5 \mu \mathrm{g} / \mathrm{ml}$ of PPE caused to $\geq 50 \%$ growth inhibition in treated cells which account for the high toxicity profile of $60 \%$ methanolic extract of PS (Table1).

In case of ovarian cancer cells, the maximum growth inhibition of $78.2 \%$ was obtained at doses $100 \mu \mathrm{g} / \mathrm{ml}$.In this cell line, $20 \mu \mathrm{g} / \mathrm{ml}$ Toxol ( positive control )caused to $93.76 \%$ growth inhibition of SKOV3 cancer cells. At the other hand, dose $5 \mu \mathrm{g} / \mathrm{ml}$ and $500 \mu \mathrm{g} / \mathrm{ml}$ of PPE caused to the lowest growth inhibition of $63.78 \%$ and $63.41 \%$. The mean growth inhibition in these cells was $69.43 \%$.

In MCF-7 cancer cells, the maximum growth inhibition of $83.7 \%$ was obtained at doses $5 \mu \mathrm{g} / \mathrm{ml}$, value comparable to that of $20 \mu \mathrm{g} / \mathrm{ml}$ Toxol which caused to $95.1 \%$ growth inhibition of MCF-7 breast adenocarcinoma cells . The lowest growth inhibition of $76.54 \%$ was obtained at dose $500 \mu \mathrm{g} / \mathrm{ml}$ of PPE. The mean growth inhibition was $82.76 \%$ (Table1, Figure 2).

In PC-3 prostate adenocarcinoma cells, PPE caused to the maximum growth inhibition of $84.16 \%$ and $84.0 \%$ at doses $250 \mu \mathrm{g} / \mathrm{ml}$ and $500 \mu \mathrm{g} / \mathrm{ml}$, respectively. In this cell line, $20 \mu \mathrm{g} / \mathrm{ml}$ Toxol caused to $93.1 \%$ growth inhibition of PC-3 cancer cells meanwhile dose $20 \mu \mathrm{g} / \mathrm{ml}$ of PPE caused to the lowest growth inhibition $73.7 \%$. The mean growth inhibition in these cells was $78.3 \%$ (Table1, Figure 2).

In case of A549 cancer cells, the maximum growth inhibition of $80.0 \%$ was obtained at doses $250 \mu \mathrm{g} / \mathrm{ml}$ $.20 \mu \mathrm{g} / \mathrm{ml}$ Toxol caused to $90.25 \%$ growth inhibition of
A549 cells. In this cells, dose $5 \mu \mathrm{g} / \mathrm{ml}, 20 \mu \mathrm{g} / \mathrm{ml}, 100 \mu \mathrm{g} /$ $\mathrm{ml}$ and $500 \mu \mathrm{g} / \mathrm{ml}$ caused to the lowest growth inhibition of $\sim 76.0 \%$. The mean growth inhibition in these cells was $77.46 \%$ (Table1, Figure 2).

In contrast to high antioxidant activity of peel part of fruit, there are handful studies that aimed to evaluate its cytotoxicity. In study by Elango et al in 2011 ,GC-MS analysis of the methanolic extract of the pomegranate peel from Kabul Varity showed a total of six compounds. Among the six compounds, GA was found to present in higher quantity which was followed by EA and quercetin. Following, the toxicity of GA was evaluated on A549 cancer cells by MTT and apoptosis assay. In this study, authors observed increased level of reactive oxygen species in the cells treated with GA at the concentrations of 10 and $20 \mu \mathrm{g} / \mathrm{ml}$. Moreover, MTT assay showed that GA reduced the cell viability to values lower then $50 \%$ at dose $20 \mu \mathrm{g} / \mathrm{ml}$ (Elango et al., 2011).

In another study by Sine Sepehr et al. (2012), authors investigated cytotoxicity and apoptotic effects of PPE and PSE extract of Iranian Pomegranate on proliferation of PC-3 cells. In this study, PPE caused to the maximum growth inhibition of $65 \%$ at doses $600 \mu \mathrm{g} / \mathrm{ml}$ in a dose dependant manner. $\mathrm{IC}_{50}$ was obtained at doses $250.21 \mu \mathrm{g} /$ $\mathrm{mL}$ in these cancer cells. In our experiment, in a dose independent manner, PPE caused to the maximum growth inhibition of $84.16 \%$ at dose $250 \mu \mathrm{g} / \mathrm{ml}$, values comparable to $20 \mu \mathrm{g} / \mathrm{ml}$ Toxol with a $93.1 \%$ growth inhibition on PC-3 cells . Moreover, $\mathrm{IC}_{50}$ (dose to suppress $50 \%$ cell growth) was determined at doses below $5 \mu \mathrm{g} / \mathrm{ml}$. These differences could be attributed to the antioxidant potency of prepared extracts, as ethanolic extracts used by above authors show lower polyphenolic content compared to methanolic extract used in our study. Notably, there was no significant difference between the cytotoxicity of different doses and even in case of in MCF-7 cells, dose $5 \mu \mathrm{g} / \mathrm{ml}$ resulted in more suppression compared to $500 \mu \mathrm{g} / \mathrm{ml}$ suggesting that an optimal biological dose is more important and relevant than a maximally tolerated one.

Furthermore, our results indicated that in all cancer cells, PPE reduced the cell viability to values below $40 \%$, even the lowest doses. In this regard, MCF- 7 breast adenocarcinoma cells were the most responsive cells to antiprolifreative effects of PPE with a maximum mean growth inhibition of $81.03 \%$ vs. $69.43 \%, 79.3 \%, 77.46 \%$ in SKOV3, PC-3 and A549 cells, respectively. It seemed that SKOV 3 ovarian cancer cells were the least responsive cells to cytotoxic properties of PPE compared to the other studied cancer cells. This finding could be partly explained by different responsiveness of studied cancer cells to the anti-estrogenic activity of polyphenolic and flavonoid compounds in the PPE which could interfere with aromatase activity and so hinder estrogen synthesis which act as a growth factor on cells that represent the esterogen receptors as well as MCF-7 and SKOV3 (Balunas et al., 2008). However, on the contrary, although SKOV 3 ovarian cancer is ER+ but their proliferation is not dependent upon estrogen, so these cells are least sensitive to antiprolifreative activity of PPE compared to other esterogen and androgen sensitive cancer cells including MCF-7, PC-3 and A549 cancer cells. 
Our results indicated that hydoalcholic extract of PPE possess a high potency to inhibit proliferation of different tumors cells in a dose independent manner which requires precise dose optimization. Moreover, the antiprolifreative effects of PPE seems to be tumor type specific, as hormone dependant cancer cells showed a high responsiveness to antitumoral effects of this extracts .

\section{Acknowledgements}

This study is funded by a grant from Student Research Committee (SRC), Tabriz, Iran .

\section{References}

Abbasi MM, Khiavi MM, Monfaredan A, et al (2014a). DOXMTX-NPs augment p53 mRNA expression in OSCC model in rat: effects of IV and oral routes. Asian Pac J Cancer Prev, 15, 8377-82.

Abbasi MM, Monfaredan A, Hamishehkar H, et al (2014b). New formulated "DOX-MTX-loaded nanoparticles" downregulate HER2 gene expression and improve the clinical outcome in OSCCs model in rat: the effect of IV and oral modalities. Asian Pac J Cancer Prev, 15, 9355-60.

Abbasi MM, Monfaredan A, Hamishehkar H, et al (2014c). Novel DOX-MTX nanoparticles improve oral SCC clinical outcome by down regulation of lymph dissemination factor VEGF-C expression in vivo: oral and IV modalities. Asian Pac J Cancer Prev, 15, 6227-32.

Balunas MJ, Su B, Brueggemeier RW, et al (2008). Natural products as aromatase inhibitors. Anticancer Agents Med Chem, 8, 646-82.

Brand-Williams W, Cuvelier M, Berset C (1995). Use of a free radical method to evaluate antioxidant activity. LWT-Food Science Technol, 28, 25-30.

Elango S, Balwas R, Vijaya Padma V (2011). Gallic acid isolated from pomegranate peel extract induces reactive oxygen species mediated apoptosis in A549 cell line. J Cancer Therapy, 2, 638-45.

Jahanban- Esfahlan A, Jahanban- Esfahlan R, jamei R, et al (2012). Morphology and physicochemical properties of 40 genotypes of almond (Amygdalus communisL.) fruits. Eur J Experimental Biol, 2, 2456-64

Jahanban- Esfahlan A, Jamei R, Jahanban-Esfahlan R (2010). The importance of almond (Prunus amygdalusL.) and its by-products. Food Chem, 120, 349-60.

Jahanban Esfahlan R, Zarghami N, Rahmati-Yamchi M, et al (2011). Quantification of steroid receptors gene expression in breast cancer patients: possible correlation with serum level of adipocytokines. J Cancer Therapy, 2, 659-65.

Lansky EP, Newman RA (2007). Punica granatum(pomegranate) and its potential for prevention and treatment of inflammation and cancer. J Ethnopharmacol, 109, 177-206.

Shafie SM, Liotta LA (1980). Formation of metastasis by human breast carcinoma cells (MCF-7) in nude mice. Cancer Letters, 11, 81-7.

Sineh Sepehr K, Baradaran B, Mazandarani M, et al (2012). Studies on the cytotoxic activities of punica granatum 1 . var. spinosa (apple punice) extract on prostate cell line by induction of apoptosis. ISRN Pharm, 2012, 547942.

Singh RP, Chidambara Murthy KN, GK J (2002). Studies on the antioxidant activity of pomegranate (Punica granatum) peel and seed extracts using in vitro models. J Agric Food Chem, 50, 81-6.

Singleton V, Rossi JA (1965). Colorimetry of total phenolics with phosphomolybdic-phosphotungstic acid reagents. Am
$J$ Enol Viticult, 16, 144-58.

Syed DN, Afaq F, Mukhtar H (2007). Pomegranate derived products for cancer chemoprevention. Semin Cancer Biol, 17, 377-85.

Valiyari S, Jahanban-Esfahlan R, Zare Shahneh F, et al (2013). Cytotoxic and apoptotic activity of scrophularia oxysepala in MCF-7 human breast cancer cells. Toxicol Environ Chem, 95, 1208-20.

Zhishen J, Mengcheng T, Jianming W (1999). The determination of flavonoid contents in mulberry and their scavenging effects on superoxide radicals. Food Chemistry, 64, 555-9. 